\title{
IN VITRO CYTOTOXICITY EFFECT ON MCF-7 CELL LINE OF CO-ENCAPSULATED ARTESUNATE AND CURCUMIN LIPOSOME
}

\author{
SARVESH SHARMA ${ }^{1}$, VIMAL KUMAR ${ }^{2}$ \\ 1Department of Pharm, Biotechnology, LNCP, Bhopal, ${ }^{2}$ Institute of Pharmacy Nirma University, Ahmedabad \\ Email: sarbiotech@yahoo.co.in
}

Received: 25 Oct 2016 Revised and Accepted: 17 Jan 2017

\begin{abstract}
Objective: Cancer drug delivery has focused using novel carrier system due to their high drug loading and release controlled property and minimum side effect. Artesunate (ART) and curcumin (CUR) are proved natural herbal lead chemotherapeutics used as Chinese and Indian food. But due to its low absorption and the poor bioavailability limits its clinical efficacy. The object of the present work was to investigate the cytotoxic vs apoptotic effect of these herbal lead molecules in the co-encapsulated liposome formulation.

Methods: ART and CUR liposome were prepared by thin film hydration method. Because of their opposite solubility nature, ART loaded in the aqueous phase at pH 7.4 while CUR is present in the central core through lipophilic interaction. In vitro cytotoxicity action of the free and liposomal formulation was performed by MTT assay.

Results: Physiochemical parameters were evaluated and compared to the co-encapsulated formulation of containing both molecules. The mean diameter around $200 \mathrm{~nm}$, low polydispersity index and co-encapsulation efficiency were found to be $90 \%$. Co-encapsulation in nanometer size is beneficial for uptake and photo-stability of a drug. The in vitro cytotoxic effect of the co-encapsulated formulation was shown a better result than individual drug and also gives the clue for apoptosis. $\mathrm{IC}_{50}$ value for ART, CUR and Liposome was found to be $297.61 \mu \mathrm{g} / \mathrm{ml}$ and $60.60 \mu \mathrm{g} / \mathrm{ml}$ respectively. The result explained the co-encapsulation of curcumin with artesunate is show an ameliorative effect for repositioning therapeutic efficacy of the drug.
\end{abstract}

Conclusion: We observed that human breast cancer MCF-7 cells were relatively resistant to ART and sensitive to CUR. Treatment with ART plus CUR had a synergistic cytotoxic, and apoptotic effect was mediated by up regulation of DR4 and DR5 m RNA expression.

Keywords: In vitro cytotoxicity, Lipophilic interaction, MCF-7

(c) 2016 The Authors. Published by Innovare Academic Sciences Pvt Ltd. This is an open access article under the CC BY license (http://creativecommons.org/licenses/by/4. 0/)

DOI: http://dx.doi.org/10.22159/ijpps.2017v9i3.15872

\section{INTRODUCTION}

Liposomes are versatile drug delivery carriers which can be used to solve problems of drug solubility, instability and rapid loss. Hydrophilic and hydrophobic drugs can be associated with liposomes. Liposomes can function as sustained release system for drugs and the rate of release can be manipulated. Substantial changes in pharmacokinetics which often accompanies the association of the drug with liposomes. New formulations of liposomes sterically stabilized with substance like surface-grafted polyethylene glycol have circulating half-lives in humans of up to 2 d. In the direction of enhancing the therapeutic effect and reduce toxicity and frequency of drug administration, different novel drug delivery carriers have been developed. Breast cancer in women is a form of malignancy due to changing lifestyle; internal hormonal or biochemical changes are a probable cause of high incidence and mortality for this disease. The characteristic feature of breast cancer can be presence or absence of estrogen receptor (ER), progesterone receptor (PR) and human epidermal growth factor-2 (HER-2).

Tumor necrosis factor related apoptosis inducing ligand (TRAIL), a tumor necrosis factor superfamily member has been shown to induce apoptosis [11]. TRAIL can bind to 5 different receptors i.e. TRAIL-R1 (death receptor 4 DR4), TRAIL-R2 (DR5), TRAIL-R3 (decoy receptor, DcR1), TRAIL-R4 (DcR2), and osteoprotegerin (OPG). DR4 and DR5 are the death receptors that signal apoptosis, whereas DcR1, DcR2, and OPG are considered antagonistic because they are unable to induce such signalling due to lack of intracellular death domain or because they are secreted molecule. TRAIL triggers apoptosis through binding to its receptors DR4 and or DR5 in various cancer cell types but not in most normal cells $[9,10]$.

Artesunate is an effective antitumor drug used to the management of breast cancer. Besides its clinical utility is limited by its optimum dose calculation, toxic effects like myelo-suppression, nausea, vomiting and renal and cardiotoxicity [1]. Similarly, Curcumin is well-known chemo preventive and chemotherapeutic choice of the drug candidate to control different types of cancer, but their low solubility and bioavailability rapid intestinal and hepatic metabolism are the constraints, so incorporation of these molecules in novel delivery system approaches is demanded to improve its potential. Previous research suggests the positive effects of the combination of curcumin and some polyphenols in oxidative stress markers and chemoprevention [2, 3].

The mechanism of action of artesunate against cancer is not clear but in vitro testing for various cell lines proved its cytotoxic behavior [4] But Curcumin has the variety of biological activity and pharmacological action, such as anti-inflammatory, anti-carcinogenic and anti-virus properties. Recent research suggests curcumin has been inhibiting cell proliferation in a various human cancer cell line and has been used to prevent as well as treat cancer [5].

Several limitations related to systemic administration of single-drug chemotherapy like high clearance, low bioavailability, and multidrug resistance. Single drug therapy may not potent to suppress all cancers cell due to unequal distribution within tumors. Coencapsulation of these herbal lead molecules in liposome gives the prospect of newer approaches to treating cancer. The vesicular systems are capable of stabilizing photo labile substance, controlling drug release, improved effectiveness and increase the biodistribution of the drug. In the present research, we investigate the comparison of free drug combination and drug combination in liposome through in vitro study. So first we evaluated the physicochemical characteristic of formulations and then investigated the cytotoxic effect of the drug. We formulated liposome containing artesunate and curcumin in equimolar concentration. The in vitro cytotoxicity was investigated using a spectrophotometric method [8]. 


\section{MATERIALS AND METHODS}

\section{Material}

3-(4,5-Dimethylthiazol-2-yl)-2,5-diphenyltetrazolium bromide (MTT) were obtained from Sigma Aldrich (Germany). Roswell Park Memorial Institute (RPMI 1640) foetal bovine serum (FBS) and trypsin were purchased from GIBCO (Germany). All solvents used were HPLC grade from Renkem, India. Curcumin and Artesunate were obtained as gift sample from IPCA, Ratlam Laboratories. Cholesterol, soya phosphatidylcholine (SPC) was purchased from sigma-aldrich Bangalore. Potassium dihydrogen phosphate, Disodium hydrogen phosphate, sodium chloride chloroform and methanol were purchased from Qualigance Chemicals Mumbai, India.

\section{Preparation of liposome suspension}

Conventional liposomes were prepared according to the thin film hydration methods according to the optimised molar ratio of lipid and cholesterol [7]. Accurately weighed quantities of curcumin (10 $\mathrm{mg})$, soya lecithin $(09 \mathrm{mg})$ and cholesterol $(01 \mathrm{mg})$ were dissolved in chloroform and methanol (2:1) $(10 \mathrm{ml})$. A thin film of the lipidcontaining drug was allowed to form on the walls of the round bottom flask by evaporating solvent under reduced pressure using a rotary vacuum evaporator (BUCHI type, Lab India, Mumbai) at a temperature $60{ }^{\circ} \mathrm{C}$ and $30 \mathrm{rpm}$. Residual solvent was evaporated overnight by storing the thin film in a vacuum desiccators. To form MLVs, this layer was hydrated with $10 \mathrm{ml}$ of saline containing $10 \mathrm{mg}$ artesunate, while mixing the flask, which was maintained at a temperature $70{ }^{\circ} \mathrm{C}$ and $30 \mathrm{rpm}$ for $1 \mathrm{~h}$. The liposomal suspension was then centrifuged at $5000 \mathrm{rpm}$ for $30 \mathrm{~min}$ to separate the free drug and then the pellet of MLVs was resuspended in normal saline. The resulted suspension was sonicated by probe sonicator (Lark Ultrasonicator) for $10 \mathrm{~min}$ and filtered with 0.2 microns to get small unilamellar vesicles.

\section{Size, polydispersity, zeta potential profile and microscopy}

All the liposomal formulation were examined for their morphological attributes using a trinocular compound microscope (Optics India) at different magnification and selected formulation to go for further evaluation.

Size, polydispersity and zeta potential were measured by photon correlation spectroscopy. For this determination, $20 \mu \mathrm{l}$ of liposomal dispersion were diluted 100 folds with saline $(0.9 \%$ Sodium chloride). Measurement was carried out at the set temperature of $25 \pm 2{ }^{\circ} \mathrm{C}$ using a Zetasizer (Malvern 6.01, Instruments. UK)

\section{Transmission electron microscopy (TEM)}

It was employed to observe the internal structure of liposome sample with negative staining methods. The sample was diluted 30 folds with distilled water. Equal volume of diluted sample and $2 \%$ ammonium molybdate solution were combined and left of $3 \mathrm{~min}$ at ambient condition. A drop of this solution was placed on a formvarcarbon coated copper grid (200 mesh, $3 \mathrm{~mm}$ diameter HF 36) for 5 min. The excess liquid was drawn off by filter paper. After drying the grid at room temperature for $5 \mathrm{~min}$, micrograph was made using Philips CM 20 (TEM) camera.

\section{Cell culture}

The human breast cancer cell line (NCCS, Pune) was cultured in RPMI- 1640 medium supplanted with $10 \% \mathrm{v} / \mathrm{v}$ fetal calf serum and $100 \mathrm{U} / \mathrm{ml}$ ampicillin and $100 \mathrm{mg} / \mathrm{ml}$ streptomycin and $2 \mathrm{mmol} \mathrm{L}-$ Glutamine incubated in $5 \% \mathrm{CO}_{2}$ at $37^{\circ} \mathrm{C}$.

\section{MTT cytotoxicity assay}

Cytotoxicity was analyzed by MTT assay. A blank control group (RPMI-1640), a negative control group (untreated cells), alone Artesunate and Curcumin treated group was designed for this experiment. In short $100 \mu \mathrm{l}$ exponentially growing cancer cell suspension $\left(1 \mathrm{X} 10^{6}\right)$ were seeded into each well of 96-well plate. Artesunate and Curcumin were then added to each well. The final concentration of Artesunate and Curcumin was 10 to $100 \mu \mathrm{g} / \mathrm{ml}$. During incubation at $37^{\circ} \mathrm{C}$ for $24 \mathrm{~h}, 20 \mu \mathrm{l}$ MTT $(5 \mathrm{mg} / \mathrm{ml}$ final concentration) was added to each well. The plates were then incubated at $37{ }^{\circ} \mathrm{C}$ for an additional $4 \mathrm{~h}$ to allow MTT to form formazan crystals by reacting with metabolically active cells. The formazan crystals were solubilized at $150 \mu \mathrm{l}$ DMSO at $37{ }^{\circ} \mathrm{C}$ for 10 min. The absorbances of reaction were measured at $570 \mathrm{~nm}$ using a microplate reader (Bio-Red model 680). Cell Viability was calculated by the formula: Cell Viability (\%) = (absorbance of the treated wellsabsorbance of the blank control wells)/(absorbance of negative control well-absorbance of the blank control wells) x 100. All MTT experiments were performed in triplicates.

The $50 \%$ inhibitory concentration (IC 50 ) of a $24 \mathrm{~h}$ exposure, defined as the drug concentration resulting in $50 \%$ reduction of cell viability, were then determined from curves of reagent concentration versus cell viability at $24 \mathrm{~h}$ of incubation for the cell line analyzed. Cell sensitivity to the drug was evaluated by the $\mathrm{IC}_{50}$ value. $\mathrm{An}_{\mathrm{IC}} \mathrm{C}_{50<} 80 \mu \mathrm{g} / \mathrm{ml}$ indicated that the cell was sensitivity to the drug, while an $\mathrm{IC}_{50} \geq 80 \mu \mathrm{g} / \mathrm{ml}$ indicated that cells were relatively resistant to the drug [20].

\section{Toxicity of the combination of artesunate and curcumin}

The concentration of Artesunate and Curcumin combination were set as follows:

Artesunate and Curcumin $(10-80 \mu \mathrm{g} / \mathrm{ml})$ on the basis of the effect on cell viability. Cell viability after $24 \mathrm{~h}$ exposure was then assayed by the MTT assay. A blank control group, a negative control group, Artesunate alone group, Curcumin alone group, Artesunate with Curcumin group (Cell treated with Artesunate and Curcumin) and Liposomal formulation were employed for this experiment.

\section{Evaluation of synergistic effect}

The synergistic effect of Artesunate and Curcumin was analyzed by the Webb coefficient [6]. Predicted cell viability (C) was calculated by the equation $C=a \times b / 100$, where $a$ and $b$ indicate cell viability after the use of each agent. Synergism of drug interaction was indicated by a cell viability of $\leq 70 \%$ of predicted value. Based on the synergistic effect observed, the optimum concentration of $0.1 \mu \mathrm{g} / \mathrm{ml}$ Artesunate and $0.5 \mu \mathrm{g} / \mathrm{ml}$ Curcumin were chosen for all later studies.

\section{Cell morphology}

Experiments were divided into four groups as follows: Artesunate alone group (cells treated with $0.1 \mu \mathrm{g} / \mathrm{ml}$ ART), Curcumin alone group (cells treated with $0.5 \mu \mathrm{g} / \mathrm{ml} \mathrm{CUR}$ ), combination group (cells treated

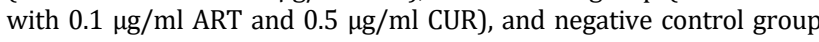
(untreated cells). Exponentially growing tumor cells were seeded onto 96-well plate a density of $1 \times 10^{6} / \mathrm{ml}$ cells/well. Artesunate and or Curcumin were added to each well. After incubation at $37^{\circ} \mathrm{C}$ for $24 \mathrm{hr}$, morphological cell changes were observed under a phase contrast trinocular microscope at 1000X (A55-Olympus).

\section{DNA fragmentation assay}

MCF-7 cells $\left(2 \times 10^{6}\right)$ were suspended in a minimal volume of DMEM medium, $2 \mu \mathrm{l}$ trypsin and different drug and formulation concentration were added and then make the final volume to $2 \mathrm{ml}$. It was incubated at $37^{\circ} \mathrm{C}$ for various $\mathrm{h}$ (from 1-24 h). After incubation centrifuge, the cells at $10,000 \mathrm{rpm}$ for $10 \mathrm{~min}$, discard the medium and wash the cells for 2 times in NTE buffer. Now suspend the cells in $2 \mathrm{ml} \mathrm{NTE}$ buffer and $2 \%$ trypsin $(100 \mu \mathrm{g} / \mathrm{ml})$ and add $20 \%$ SDS $(25 \mu \mathrm{l} / \mathrm{ml})$ and proteinase $\mathrm{K}(100 \mu \mathrm{g} / \mathrm{ml})$. Again incubate the cells at $37^{\circ} \mathrm{C}$ for overnight. Add $1 \mathrm{ml}$ NTE buffer-saturated phenol and $1 \mathrm{ml}$ chloroform and shake the vial 12 times (turning up and down slowly) centrifuge at $10,000 \mathrm{rpm}$ for $10 \mathrm{~min}$ (2 phases are seen) and transfer the upper portion to another vial and add $1 \mathrm{ml}$ chloroform, repeat this for 3 times. To this RNase was added and incubated at $35^{\circ} \mathrm{C}$ for $2 \mathrm{~h}$. Centrifuge the vial at $10,000 \mathrm{rpm}$ for $10 \mathrm{~min}$ and decant the supernatant and take the pellet (DNA) and dissolve in TAE buffer. Then the dissolved DNA is subjected to horizontal electrophoresis (Genei, Banglore) on $0.8 \%$ agarose at $2 \mathrm{~V} / \mathrm{cm}^{2}$ for 16 $\mathrm{hr}$ and visualized under UV trans-illuminator (Sunshine Instruments) after staining with ethidium bromide. [19]

\section{Western blot analysis}

Cells incubated with ART $(0.1 \mu \mathrm{g} / \mathrm{ml})$ or CUR $(0.5 \mu \mathrm{g} / \mathrm{ml})$ alone or in combination for $24 \mathrm{hr}$ were lysed in lysis buffer. Protein concentration was determined by bi-cinchonic acid methods. $40 \mu \mathrm{g}$ 
of cell lysate protein was subjected to $4-15 \%$ gradient SDS-PAGE using a Tris-glycine system and then the gel was electroblotted onto polyvinylidene difluoride membranes for $45 \mathrm{~min}$. The membranes were then incubated with 5\% non-fat dry milk in PBS for $1 \mathrm{hr}$ in order to block nonspecific binding sites, and then incubated with the appropriate primary antibody concentration (1:2000 for caspase-9, 1:400 for Bax and 1:2000 for $\beta$-actin) for $2 \mathrm{~h}$ at $37{ }^{\circ} \mathrm{C}$ in $5 \%$ non-fat dry milk. The membrane was subsequently rinsed in PBS and then incubated for $2 \mathrm{~h}$ at $37{ }^{\circ} \mathrm{C}$ with secondary antibody (HRP conjugated anti-rabbit or antimouse IgG) at 1:2000 dilution. After incubation, membranes were rinsed and blots were visualised by incubation with enhanced chemiluminescence detection reagents. Signal density was obtained by scanning exposed X-ray films on a Bio-Rad imaging system. Normalized density was obtained by dividing the rough density values of a sample band by those of the loading control band ( $\beta$-actin). Immunoblotting data were quantitated from at least three experiments.

\section{Statistical analysis}

All of the tests were done in triplicate. The result was expressed as a mean \pm standard deviation. A probability level less than $5 \%(p<0.05)$ was considered significant. The student t-test, one-way ANOVA performed by Microsoft Excel.

\section{RESULTS}

In order to overcome the undesirable side effects of drugs, synergistic combination of two or more drugs is a flexible strategy (16). In comparison with single drug delivery system, co-delivery of drugs through nanocarriers and convey them to the same cancer cell simultaneously $(17,18)$. All formulation were analyzed in terms of size (nm), Polydispersity (Pd) and zeta potential were measured by photon correlation spectroscopy, as summarized in the fig. 1. The correlation coefficient is larger to 0.9 it indicates the signal to noise ratio is good.

The mean diameter of Artesunate based liposome was $100 \mathrm{~nm}$ and it is suitable for the intra-peritoneal administration. Pd is a dimensionless measure of the broadness of size distribution and value were calculated for each peak as peak width/mean diameter. Zeta potential is around-30mv; this is an evidence for a bigger dispersion electrostatic stabilization in physiological solution.
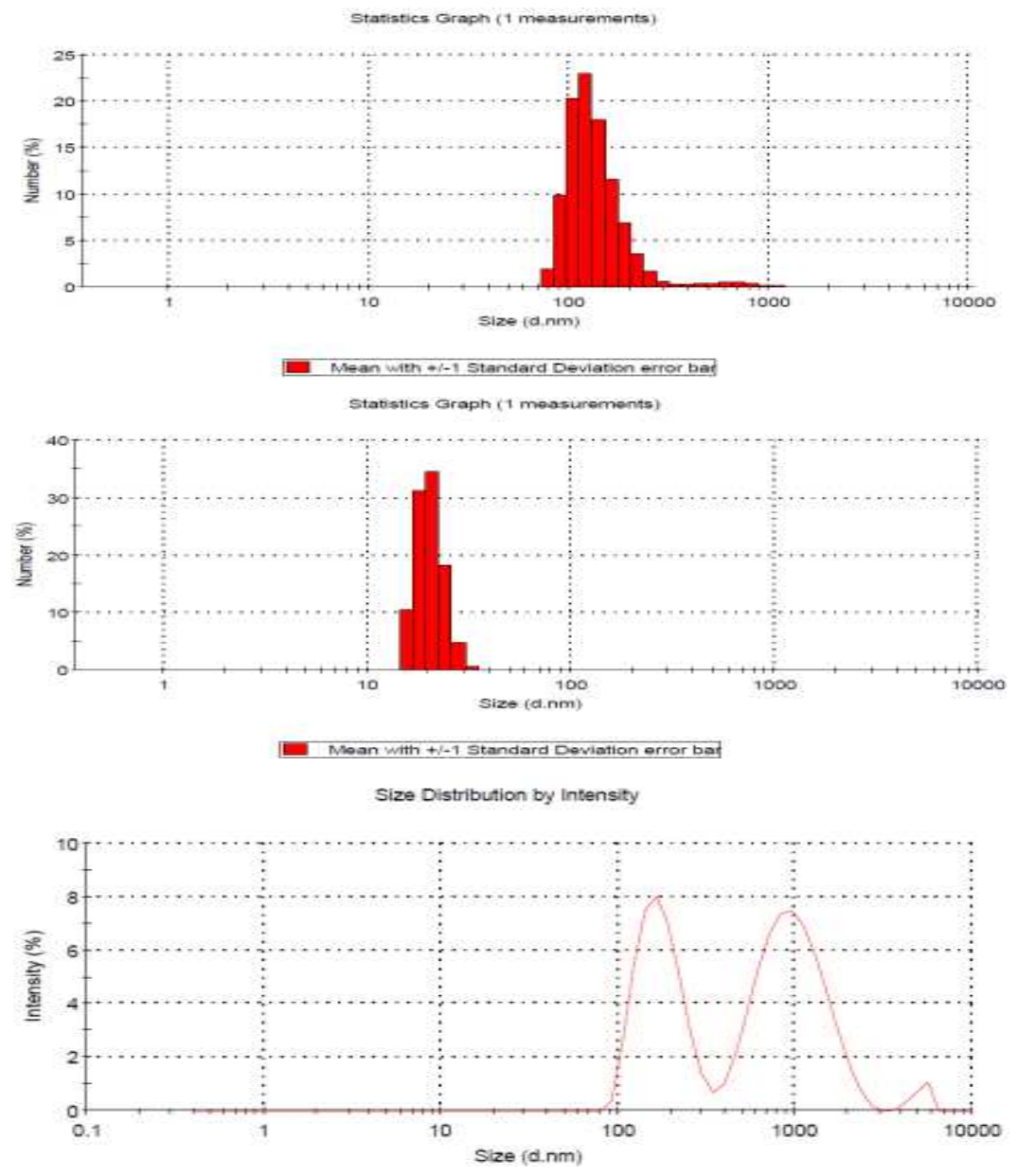

Size Distribution by Intensity

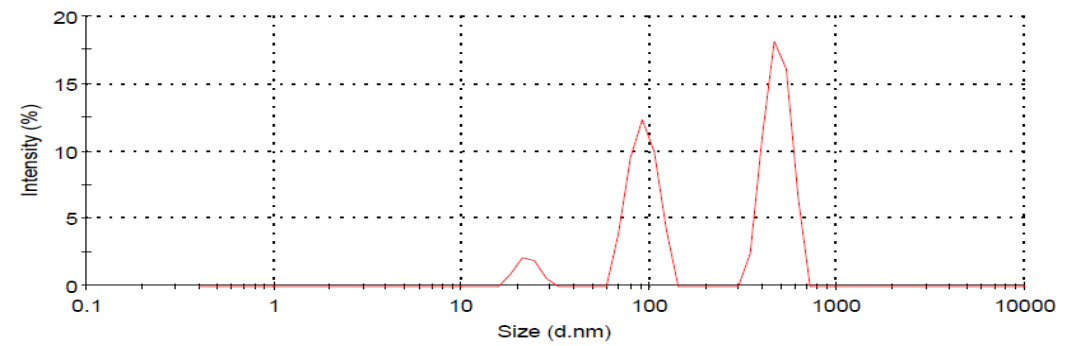

Fig. 1: Size and zeta potential profile of Liposome containing combination of Artesunate and curcumin 
Table 1: Human breast cancer cell line (MCF-7) \% controlled growth

\begin{tabular}{|c|c|c|c|c|c|c|}
\hline \multirow[t]{2}{*}{ S. No. } & \multirow[t]{2}{*}{ Drug and formulation } & \multicolumn{5}{|c|}{ Drug concentration $(\mu \mathrm{g} / \mathrm{ml})$} \\
\hline & & 10 & 20 & 40 & 60 & 80 \\
\hline 1 & Artesunate & $3.6 \pm 0.18$ & $-3.9 \pm 0.19$ & $-5.5 \pm 0.27$ & $-9.2 \pm 0.46$ & $-14.6 \pm 0.73$ \\
\hline 2 & Curcumin & $-22.9 \pm 1.14$ & $-28.4 \pm 1.42$ & $-30.3 \pm 2.46$ & $-32.4 \pm 1.62$ & $-53.1 \pm 2.65$ \\
\hline 3 & Artesunate+Curcumin & $-11.8 \pm 0.59$ & $-17.2 \pm 0.86$ & $-23.0 \pm 1.15$ & $-37.6 \pm 1.88$ & $-43.6 \pm 2.18$ \\
\hline 4 & Liposome Formulation & $-20.4 \pm 1.02$ & $-26.8 \pm 1.34$ & $-32.2 \pm 1.61$ & $-40.6 \pm 2.03$ & $-54.2 \pm 2.71$ \\
\hline 5 & Adriamycin (Doxorubicin) & $-35.1 \pm 1.7$ & $-40.7 \pm 1.9$ & $-44.4 \pm 2.2$ & $-46.2 \pm 2.3$ & $-49.3 \pm 2.5$ \\
\hline
\end{tabular}

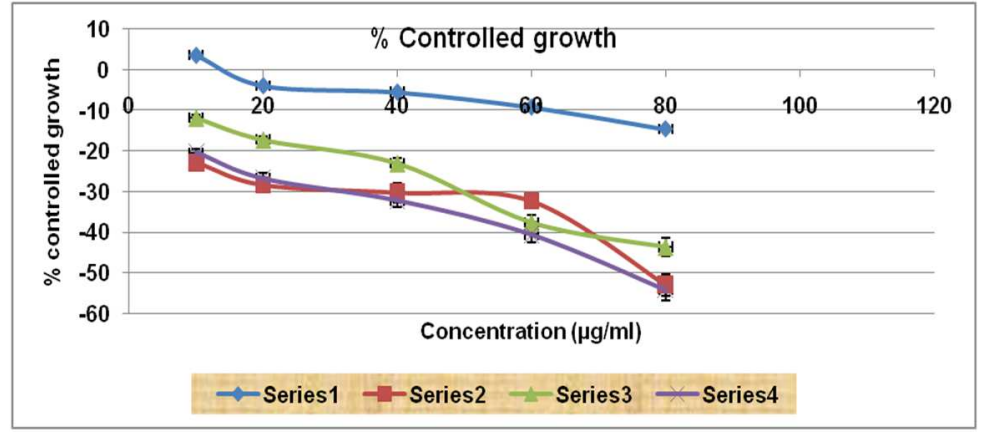

Fig. 2: Effect of single drug and combination on cell growth of human breast cancer cell line MCF-7 [series 1-ART, series 2-CUR, series 3ART+CUR and series 4-Liposomal formulation of ART+CUR]

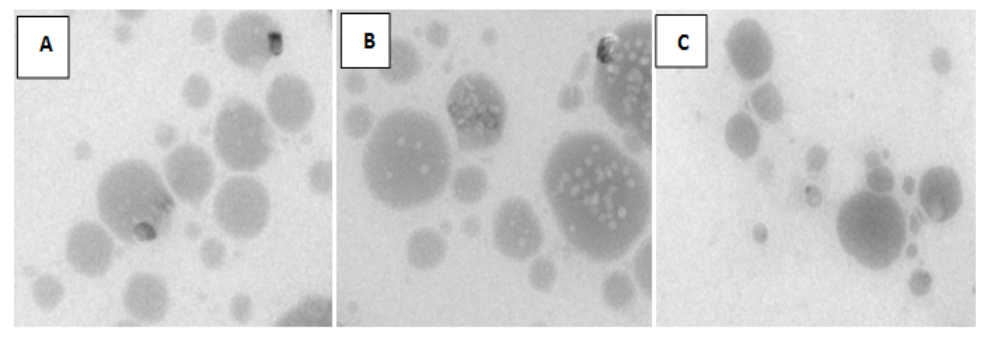

Fig. 3: TEM image of A. ART liposome B. CUR liposome C. ART+CUR liposome

\section{Effect of artesunate or curcumin alone on MCF-7 cell growth}

Twenty h exposure of MCF-7 cells to ART at a range of concentration from 0.01 to $10 \mu \mathrm{g} / \mathrm{ml}$ induce limited cell death, and there was no correlation between cell growth and ART concentration $(\mathrm{r}=0.814$, $\mathrm{P}>0.05)$. IC 50 was $297.61 \mu \mathrm{g} / \mathrm{ml}(>10 \mu \mathrm{g} / \mathrm{ml})$, advising that MCF-7 cells were relatively resistant to ART. Similarly 24-h exposure of MCF-7 cells to CUR at a range of concentration from 0.05 to 50 $\mu \mathrm{g} / \mathrm{ml}$ strongly induced cell death in a dose-dependent manner ( $\mathrm{r}=-$ $0.16, \mathrm{P}<0.05$ ). IC 50 was $60.60 \mu \mathrm{g} / \mathrm{ml}$ suggesting that MCF-7 cells were sensitive to CUR. fig. 2.

Effect of combination artesunate and curcumin on MCF-7 cell growth and evaluate the synergistic effect

Compared to ART alone a group, cell growth showed no significant difference in the combination groups of $0.005 \mu \mathrm{g} / \mathrm{ml}$ Curcumin and $0.01,0.1,1$ and $10 \mu \mathrm{g} / \mathrm{ml}$ ART, respectively ( $>0.05)$. When 0.05 or $0.5 \mu \mathrm{g} / \mathrm{ml}$ CUR was combined with $0.01,0.1,1$ and $10 \mu \mathrm{g} / \mathrm{ml} \mathrm{ART}$, respectively, showed synergistic cytotoxic effect $(\mathrm{P}<0.05)$ which was stronger in the group treated with the combination of $0.1 \mu \mathrm{g} / \mathrm{ml}$ ART and $0.5 \mu \mathrm{g} / \mathrm{ml}$ Cur $(\mathrm{P}<0.05)$ fig. 2 .

\section{Cellular changes of MCF-7 after drug treatment}

24 treatments with ART, some cells were floating and became rounder and smaller and refraction also decreased; some cell debris was observed in the medium. The cells left on the wall became rounder and smaller (fig. $4 \mathrm{~A}$ ) In CUR alone group, most cells were adhesive. The cells left on the wall underwent significant changes in morphology; the original shape was gone, cells became rounder and larger, and the cytoplasm became rougher (fig. 4 B). In the combination group, the majority of cells were floating and had irregular cells walls, and there was some cell debris in medium (fig. 4 C), whereas MCF-7 cells in the negative control group did not show obvious morphological changes (fig. 4 D).

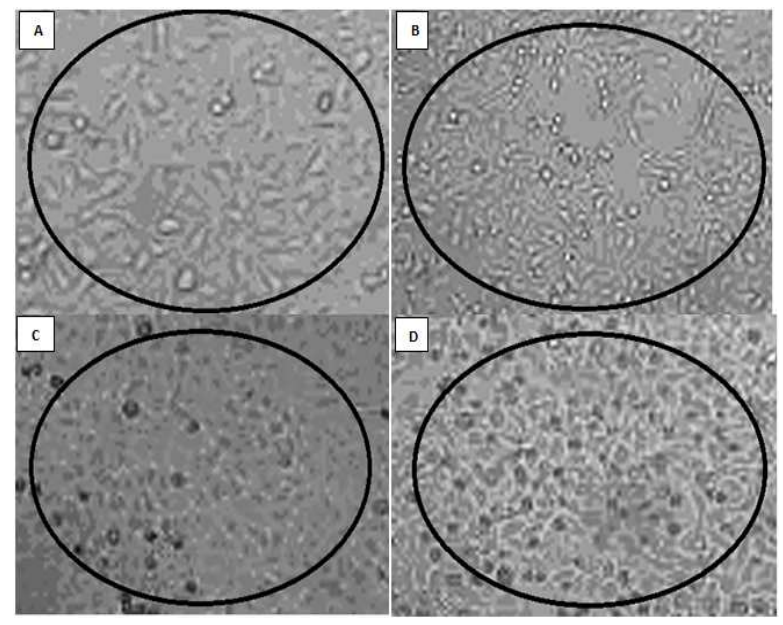

Fig. 4: Morphological changes of human breast cancer cell line MCF7 after treatment, MCF-7 cells were treated with ART $(0.1 \mu \mathrm{g} / \mathrm{ml})$ and/or CUR $(0.5 \mu \mathrm{g} / \mathrm{ml})$ for $24 \mathrm{~h}$ and the morphological changes of cells were observed under an inverted microscope $(1000 \mathrm{X})$

As shown in fig. 7 Lane 3 (Liposome of ART+CUR) had higher fragmentation than Lane 4 free ART+CUR 


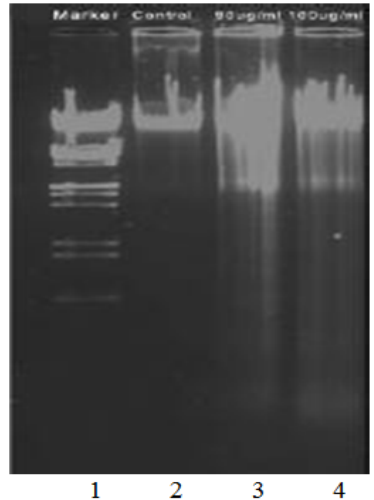

Fig. 5: DNA fragmentation of ART+CUR in MCF-7 cells

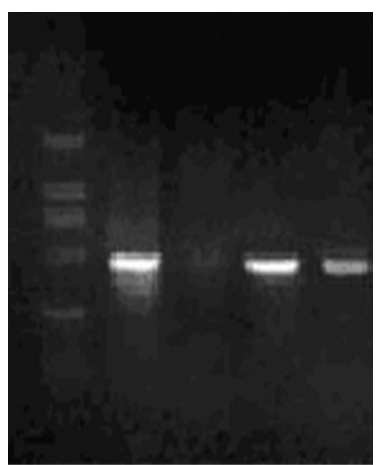

Fig. 6: Expression of ART+CUR mRNA receptor in MCF-7 cells Lane M, DL2000; lane 1, DcR2 (453 bp); lane 2, DcR1; lane 3, DR5 (502 bp); lane 4 DR4 (506 bp)

\section{DISCUSSION}

Liposome containing artesunate and curcumin were produced and showed consistent characters. Co-encapsulation did not change the properties of the formulation containing an individual drug.

It is essential to interpret the structural characteristics of liposomes such as their size and shape with the incorporation of a combination of the drug. Hence, in order to study the morphological characteristics and incorporation of Artesunate and Curcumin into the bilayer, Zetapotential and TEM analysis was performed. The morphological characteristics of liposomal formulations at an equimolar concentration of individual drug are shown in fig. 3 (A, B, C).

The release behaviour of the drug in vitro can be controlled by regulating the dissolubility, $\mathrm{pH}$ and zeta-potential of the formulation. Phosphatidyl-cholein could interact with the negatively charged (acidic) drug when incorporated into films, and this might affect drug release characteristics in the microenvironment. Cationic charge on liposome has also been shown to reduce their biodistribution between the tumor microvasculature and interstitium without impacting overall tumor uptake. The hydrophobic interaction between the drug residues provides for additional stabilization. Faster release of curcumin was also observed for curcumin loaded liposome, which may have more peripheral drug localization and hence faster release.

In this study, we observed that effect of artesunate or curcumin alone and the combination of artesunate and curcumin on MCF-7 cell growth and evaluate the synergistic effect by webb coefficient equation. The \% controlled growth and concentration relation was shown in the graphical representation in fig. 2.

After one-day treatment with ART alone group, some cells were floating and became rounder and smaller and refraction also decreased some cells debris was observed in the medium. The cells left on the wall became rounder and smaller. In the CUR alone group, the original shape was gone, cells became rounder and bigger, and the cytoplasm became rougher. While in combination group morphology of the majority of cells were floating and had irregular cell walls and there was some cell debris in the medium. The last group consider as a negative control group.

Apoptosis is one of the major processes that lead to cell death. A number of chemotherapeutic agents could induce apoptosis in malignant cell lines. artesunate and curcumin combination exerts potent to suppress the breast cancer cells. artesunate and curcumin can induce apoptosis in a broad range of human cancer cell lines while sparing most normal cell types. Thus this combination is a promising therapeutic agent against cancer because of its tumor selectivity. In this study, the data showed that human breast cancer MCF-7 cells were relatively resistant to artesunate but sensitive to curcumin. The mechanism of resistance is not clear, but it may be due to relatively low DR4 levels or relatively high DcR2 expression.

Apoptosis is controlled by multiple pathways that integrate both Intra and extracellular signals. ART controls one such apoptotic pathway by binding to its two death receptors DR4 and DR5 $[9,12]$. The extent of apoptosis induced by TRAIL is tightly regulated by the expression of these receptors and by downstream signaling. curcumin, a DNA damaging chemotherapeutic agent, is accepted as a first-line chemotherapeutic agent for breast cancer. It has been demonstrated that DNA damaging chemotherapeutic drugs could sensitize tumor cells that are resistant to TRAIL by up-regulating the expression of DR4 and DR5 in tumor cells [13-15]. We observed that human breast cancer MCF-7 cells were relatively resistant to ART and sensitive to CUR. Treatment with ART plus CUR had a synergistic cytotoxic and apoptotic effect was mediated by upregulation of DR4 and DR5 m RNA expression. The result showed that co-encapsulated artesunate and curcumin Liposome is a promising approach to improve the performance of medicines and functional foods used to prevent and treat human malignancy. Further, in vivo studies will be carried out to confirm these improved effects in the model of other critical cancer types.

\section{CONCLUSION}

Although a combination of surgery and chemotherapy has noticeably improved the survival rate of breast cancer, the application of anti-cancer drugs is still associated with significant adverse reactions, for instance, acquisition of drug-resistant phenotypes, the necessity to develop new and safe chemotherapeutic agents. Recently herbal lead molecule becoming more effective to control and prevent cancers. Experimental data showed that ART or CUR alone leads to 10 or $18 \%$ apoptosis respectively, while their combination effectively increased cell apoptosis to $37.6 \%$. These results suggest that ART combined with CUR had a synergistic apoptotic effect on MCF-7 cells. In addition, these findings also demonstrated that synergy in cytotoxicity was paralleled by synergy in apoptosis. Therefore, we believe that the synergistic antitumor effect of the combination of ART and CUR on MCF-7 cells is due to the induction of cellular apoptosis.

\section{CONFLICT OF INTERESTS}

\section{Declared none}

\section{REFERENCES}

1. Irvin W, Muss HB, Mayer DK. Symptom management in metastatic breast cancer. Oncol 2011;16:1203-14.

2. Aftab N, Vieira A. Antioxidant activities of curcumin and combinations of this curcuminoid with other phytochemicals. Phyto Res 2010;24:500-2.

3. Malhotra A, Nair P, Dhawan DK. Modulatory effects of curcumin and resveratrol on lung carcinogenesis in mice. J Phytol Res 2010;24:1271-7.

4. Berger TG, Dieckmann D, Efferth T, Schultz ES, Funk JO, Baur A, et al. Artesunate in the treatment of metastatic uveal melanoma-first experiences. Oncol Rep 2005;14:1599-604.

5. Hasan M. Liposome encapsulation of curcumin: physicochemical characterizations and effects on MCF7 cancer cell proliferation. Int J Pharm 2014;461:519-28.

6. Yen YA, Herenyiova M, Weber G. Quercetin: synergistic action with carboxy amido triazole in human breast carcinoma cells. Life Sci 1995;57:1285-92. 
7. Coradini K, Lima FO, Oliveira CM, Chaves PS, Athayde ML Carvalho LM, et al. Co-encapsulation of resveratrol and curcumin in lipid-core nanocapsules improves there in vitro antioxidant effects. Eur J Pharm Biopharm 2014;88:178-85.

8. Sharma S, Saraogi GK, Kumar V. Development of spectrophotometric methods for simultaneous determination of artesunate and curcumin in a liposomal formulation. Int J Appl Pharm 2015;7:18-21.

9. Wang S. The promise of cancer therapeutics targeting the TNFrelated apoptosis-inducing ligand and TRAIL receptor pathway. Oncogene 2008;27:6207-15.

10. Truneh A, Sharma S, Silverman C, Khandekar S, Reddy MP, Deen KC, et al. Temperature-sensitive differential affinity of TRAIL for its receptors DR5 is the highest affinity receptor. J Biol Chem 2000;275:23319-25.

11. Ashkenazi A, Holland P, Eckhardt SG. Ligand-based targeting of apoptosis in cancer: the potential of recombinant human apoptosis ligand 2/tumor necrosis factor-related apoptosis-inducing ligand (rhApo2L/TRAIL). J Clin Oncol 2008;26:3621-30.

12. McDonald ER, Chui PC, Martelli PF, Dicker DT, El-Deiry WS. Death domain mutagenesis of KILLER/DR5 reveals residues critical for apoptotic signaling. J Biol Chem 2001;276:14939-45.

13. Lacour S, Hammann A, Wotawa A, Corcos L, Solary E, Dimanche-Boitrel MT. Anticancer agents sensitize tumor cells to tumor necrosis factor related apoptosis inducing ligandmediated caspase-8 activation and apoptosis. Cancer Res 2001;61:1645-51

14. Gibson SB, Oyer R, Spalding AC, Anderson SM, Johnson GL. Increased expression of death receptors 4 and 5 synergizes the apoptosis response to combined treatment with etoposide and TRAIL. Mol Cell Biol 2000;20:205-12.

15. Henson ES, Johnston JB, Gibson SB. The role of TRAIL death receptors in the treatment of haematological malignancies. Leuk Lymphoma 2008;49:27-35.

16. Liu P, Wang Z, Brown S, Kannappan V, Erebi-Tawari P, Jiang W, et al. Liposome-encapsulated Disulfiram inhibits NFkB pathway and targets breast cancer stem cells in vitro and in vivo. Oncotarget 2014;5:7471-85.

17. Tian Y, Mao S. Amphiphilic polymeric micelles as the Nanocarrier for peroral delivery of poorly soluble anticancer drugs. Eu ODD 2012;9:687-700.

18. Yoon YI, Kwon YS, Cho HS, Heo SH, Park KS, Park SG, et al. Ultrasound-mediated gene and drug delivery using a microbubble-liposome particle system. Theranostics 2014; 4:1133-44.

19. Senthilraja P, Kathiresan K. In vitro cytotoxicity MTT assay in Vero, HepG2 and MCF-7 cell lines study of marine yeast. J Appl Pharm Sci 2016;5:80-4.

20. Moorthi C, Kumar CS, Kathiresan K. Synergistic anti-cancer activity of curcumin and bio-enhancers combination against various cancer cell lines. Int J Pharm Pharm Sci 2014;6:901-3.

\section{How to cite this article}

- $\quad$ Sarvesh Sharma, Vimal Kumar. In vitro cytotoxicity effect on MCF-7 cell line of co-encapsulated artesunate and curcumin liposome. Int J Pharm Pharm Sci 2017;9(3):123-128. 